\title{
Quantitative evaluation of corneal epithelial injury caused by $n$-heptanol using a corneal resistance measuring device in vivo
}

This article was published in the following Dove Press journal:

Clinical Ophthalmology

13 April 2012

Number of times this article has been viewed

\author{
Masamichi Fukuda' \\ Hiroshi Sasaki' \\ 'Department of Ophthalmology, \\ Kanazawa Medical University, \\ Uchinada, Japan
}

\begin{abstract}
Purpose: We attempted to develop a device for measuring electrical corneal resistance (CR) using corneal contact lens electrodes to quantitatively evaluate corneal injury in vivo. In the present study, full-thickness detachment of the corneal epithelium was induced by n-heptanol, and the feasibility of the quantitative evaluation of this injury by corneal contact lens electrodes was evaluated in vivo.
\end{abstract}

Methods: The central area of an albino rabbit's cornea was exposed to a filter paper preimmersed in n-heptanol for 1 minute to induce injury of the corneal epithelium. After induction of injury, the electrical CR was measured and the percentage of $\mathrm{CR}(\% \mathrm{CR})$ was calculated. Fluorescein solution ( $3 \mu \mathrm{L}$ ) was applied to the wound/affected area of the corneal epithelium for photography with a slit-lamp biomicroscope. The wound/affected area was measured using an image analysis system. The correlation between the $\% \mathrm{CR}$ and the wound/affected area was analyzed.

Results: As the size of the wound/affected area of the corneal epithelium increased, the $\% \mathrm{CR}$ decreased after corneal epithelium detachment. Thus, a close correlation was found between the area of corneal epithelium detachment and the \%CR.

Conclusion: The corneal resistance device that we developed was capable of quantitatively evaluating n-heptanol-induced full-thickness injuries of the corneal epithelium.

Keywords: eyes in vivo, corneal injury, corneal contact lens electrode corneal resistance device, n-heptanol

\section{Introduction}

In vitro experimental systems using cultured cells are often employed to evaluate the barrier function of the corneal epithelium as well as injuries of the corneal epithelium caused by various drugs. ${ }^{1-7}$ These experimental systems provide an excellent means for the objective comparison of the potential for cornea injury among several ophthalmic solutions; however, the extent to which these experimental models reflect the condition of the eyes in vivo remains unclear. Corneal staining, in which injured sites of the corneal epithelium are stained with fluorescein, has been extensively used as a method of clinically evaluating corneal injuries, particularly injuries of the corneal epithelium. However, objective quantification of the severity of corneal epithelium injury is difficult with fluorescein staining. The degree of the injury is generally scored subjectively, but scoring is difficult to replicate from one examination to the next, or among doctors. Thus, it is difficult to determine whether the corneal injury is worsening or improving.

At present, fluorophotometry is used clinically because it is the best way to quantitatively evaluate barrier function of the corneal epithelium. There is another possible
Correspondence: Masamichi Fukuda Department of Ophthalmology, Kanazawa Medical University, Daigaku I-I, Uchinada-machi, Kahoku-gun, Ishikawa 920-0293, Japan

Tel +817628622 II ext 34I7

Fax +81 762861010

Email fukuda@kanazawa-med.ac.jp 
method, which is based on the use of ultrasound corneal imaging. ${ }^{8}$ We recently attempted to develop an electrical corneal resistance (CR) measuring device that is composed of corneal contact lens (CL) electrodes and that can be used as a new electrophysiological method to enable simpler quantitative evaluations of the severity of drug-induced corneal injuries in vivo. The purpose of this study was to determine whether electrical CR can be used to assess the degree of injury to the corneal epithelial cells (CECs). In the present study, full-thickness detachment of the corneal epithelium was induced by n-heptanol, and the feasibility of quantitative evaluation of this injury using corneal CL electrodes was evaluated in vivo.

\section{Methods}

\section{Animals}

Twenty-four New Zealand white male rabbits (specific pathogen free) weighing between $2.5 \mathrm{~kg}$ and $3.2 \mathrm{~kg}$ were used for this study. The animals were obtained from Japan SLC Inc (Tokyo, Japan) and housed in animal facilities under an ambient illumination of $1 \mathrm{~cd} / \mathrm{m}^{2}$.

Experiments were performed on the rabbits under the following standard conditions throughout the study: room temperature, $24(2)^{\circ} \mathrm{C}$; relative humidity, 60 (10)\%; and alternating 12 hour light-dark cycles ( 8 am to $8 \mathrm{pm}$ ).

All procedures were performed with adherence to the Association for Research in Vision and Ophthalmology statement for the use of animals in ophthalmic and vision research.

\section{Corneal resistance device}

A bipolar corneal CL carrying two concentric gold wire electrodes (Mayo Corporation, Aichi, Japan) was used to measure CR. The gold wire electrodes were fixed to the inner surface of the CL, and the electrodes delivered the electrical pulses and recorded the voltage drop across the cornea. $\mathrm{CR}(\Omega)$ was calculated using the following equation:

$$
\mathrm{CR}(\Omega)=\text { Voltage }(\mathrm{V}) / \text { Current }(\mathrm{A})
$$

The resistance of the tissue was calculated by Ohm's Law: resistance $(\Omega)$ is equal to the voltage $(\mathrm{V})$ divided by the current (I in amperes). The electrical pulses were obtained from a function generator (Dagatron, Seoul, Korea), and they were delivered through a stimulus isolation unit (BSI-2; BAK Electronics Inc, Mt Airy, MD). The parameters of the electrical currents were as follows: frequency, $1000 \mathrm{~Hz}$; waveform, biphasic square waves; duration,
5 milliseconds; and current, $100 \mu \mathrm{A}$. The recordings were made using the PowerLab system (ADInstruments, Sydney, Australia).

A bipolar corneal CL carrying two concentric gold wire electrodes (an active electrode and an indifferent electrode) on the curved concave surface was placed in contact with the rabbit corneal surface at the time of measurement. The device was designed to measure the electrical resistance of the cornea by measuring the resistance between the active and indifferent electrodes using an electrical resistance meter.

The corneal resistance device (CRD; Fukuda model 2007 [patent application 2006-348160]) that was used for the measurement of the electrical CR is shown in Figure 1. The device was composed of corneal CL electrodes (Mayo Corporation), a function generator (Dagatron), an isolator (BSI-2; BAK Electronics), and a PowerLab System (ADInstruments).

The corneal CL electrodes were made of acrylic resin and were designed to have a diameter and a base curve that corresponded to the shape of the rabbit cornea. Both the active and indifferent electrodes installed on the curved concave surface were made of gold, the outer diameters were $12 \mathrm{~mm}$ (active electrode) and $4.8 \mathrm{~mm}$ (indifferent electrode), and the widths were $0.8 \mathrm{~mm}$ and $0.6 \mathrm{~mm}$, respectively. The measurement of CR was carried out under the following settings: alternating current; frequency, $1000 \mathrm{~Hz}$; rectangular waveform; duration, 5 milliseconds; and current, $100 \mu \mathrm{A}$.

\section{Creation of full-thickness detachment of the corneal epithelium \\ Corneal epithelium detachment with $n$-heptanol}

Corneal epithelium detachment was induced in rabbits using n-heptanol (Wako Pure Chemical Industries Ltd, Osaka, Japan) according to the method reported by Cintron et al. ${ }^{9}$ With this method, full-thickness detachment of the corneal epithelium can be induced while, as has been reported, the basement membrane of the corneal epithelium remains almost intact histologically. Rabbits were locally anesthetized with $0.4 \%$ oxybuprocaine hydrochloride (Benoxil ${ }^{\circledR}$; Santen Pharmaceutical Co, Ltd, Osaka, Japan). Filter papers of various diameters $(1.75,4,6$, and $9 \mathrm{~mm})$ were immersed in n-heptanol. Excess n-heptanol was removed from each filter paper using another filter paper. The filter paper was then placed in contact with the middle of the cornea for 60 seconds to induce detachment of the corneal epithelium. After detachment, the cornea was washed with $10 \mathrm{~mL}$ of physiological saline to remove the remains of the freed cells and any n-heptanol that remained on the cornea. 


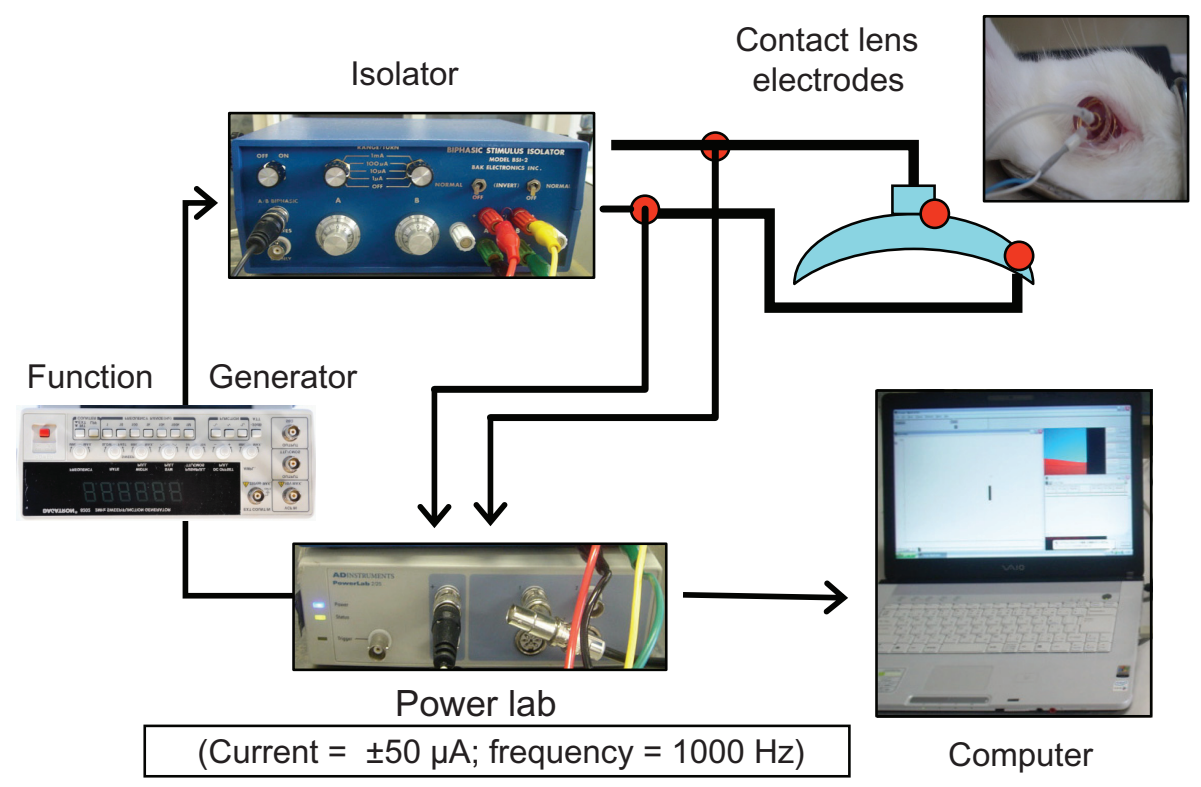

Figure I Corneal resistance device.

Notes: The parameters of the electrical currents were as follows: frequency, $1000 \mathrm{~Hz}$; waveform, biphasic square waves; duration, 5 milliseconds; and current, $100 \mu \mathrm{A}$. The recordings were made using the PowerLab system.

\section{Methods}

\section{Experiment I: evaluation by the wound/ affected area method}

Injury of the corneal epithelium was induced using a $6 \mathrm{~mm}$ diameter filter paper that had been preimmersed in n-heptanol. Immediately, 30 minutes after, and 24, 48, and 72 hours after the induction of injury (detachment), $3 \mu \mathrm{L}$ of fluorescein $(0.5 \%)$ solution was applied to the eye, which was followed by photography under a cobalt filter-attached slit-lamp biomicroscope (Carl Zeiss AG, Oberkochen, Germany). The images were analyzed with an image analysis system (ImageJ) to determine the wound/affected area. Image $\mathrm{J}$ is a computer program for scientific image analysis (National Institutes of Health Image) developed at the National Institutes of Health, USA. In this experiment, ten rabbits were used.

\section{Experiment 2: evaluation with the CRD}

Mature albino rabbits were locally anesthetized with $0.4 \%$ oxybuprocaine hydrochloride $\left(\right.$ Benoxil $\left.^{\circledR}\right)$. Next, Scopisol was applied to the eye (one drop/eye), and corneal electrodes were attached for the measurement of the electrical CR. The CR of eyes with full-thickness corneal epithelium detachment was measured as follows. A filter paper (diameter, $6 \mathrm{~mm}$ ), which was preimmersed in n-heptanol, was placed in contact with the cornea to induce corneal epithelium detachment. CR was measured 30 minutes and 24, 48, and 72 hours after the induction of injury (detachment) and was compared with the pre-injury CR. The percentage of $\mathrm{CR}(\% \mathrm{CR})$ of each eye relative to the normal eye (defined as $100 \%$ ) was calculated. $\mathrm{CR}(\Omega)$ and $\% \mathrm{CR}$ were calculated using the following equations: $\mathrm{CR}(\Omega)=$ voltage $(\mathrm{V}) /$ current $(\mathrm{A}) ; \% \mathrm{CR}=\mathrm{CR}$ after injury $\times 100 /$ CR before injury.

\section{Experiment 3: relationship between filter paper diameter and \%CR}

Filter papers of varying diameters $\left(1.7 \mathrm{~mm}\right.$ [area, $2.27 \mathrm{~mm}^{2}$, $4 \mathrm{~mm}\left[12.56 \mathrm{~mm}^{2}\right], 6 \mathrm{~mm}\left[28.26 \mathrm{~mm}^{2}\right]$, and $9 \mathrm{~mm}\left[63.59 \mathrm{~mm}^{2}\right]$ ) that had been preimmersed in n-heptanol were placed in contact with the middle of the albino rabbit cornea for 1 minute in order to induce injury of the corneal epithelium (full-thickness detachment of corneal epithelium). After 30 minutes, the wound/affected corneal area $\left(\mathrm{mm}^{2}\right)$ and $\% \mathrm{CR}$ were measured. Sixteen rabbits (16 eyes) were used for this experiment.

\section{Experiment 4: measurement of electrical resistance using the corneal chamber device (in vitro experiment)}

After removal of the eyeballs of mature albino rabbits euthanized with excessive pentobarbital sodium, a sclerocorneal piece was cut off from the eyeballs and fixed on the corneal chambermeasuring device. ${ }^{9}$ Immediately after the measurement of the resistance of the untreated cornea, a corneal epithelial defect was created on the same cornea, and CR was measured similarly. 
The corneal epithelial defect eye model was created by placing filter papers $\left(1.7 \mathrm{~mm}\right.$ [area, $2.27 \mathrm{~mm}^{2}$ ], $4 \mathrm{~mm}$ [12.56 $\left.\mathrm{mm}^{2}\right], 6 \mathrm{~mm}\left[28.26 \mathrm{~mm}^{2}\right]$, and $\left.9 \mathrm{~mm}\left[63.59 \mathrm{~mm}^{2}\right]\right)$ containing $n$-heptanol in contact with the corneal epithelial side of the sclerocorneal piece for 1 minute. The measurement of CR was performed in the following manner. The sclerocorneal piece was fixed on the corneal-chamber measuring device, and the lacrimal side and aqueous humor side were filled with a phosphate buffer solution $(2 \mathrm{~mL})$. Disc electrodes (model: F-E5GH, Disc Electrode: Gold; diameter, $10 \mathrm{~mm}$; Grass Technologies, West Warwick, RI) were set up on both sides at $25^{\circ} \mathrm{C}$, and an electrical current was passed through the active electrode and the indifferent electrode by the electrical resistance measuring device 1 minute after attachment. The electrical resistance of the cornea was measured, and then the obtained value was converted to the $\% \mathrm{CR}$. In addition, the ratios of CR in the corneal epithelium and corneal stroma/endothelium were calculated.

\section{Statistical analysis}

Results of corneal injury (in vitro) and those using a corneal resistance measurement (in vivo) were obtained from at least four experiments. A student's $t$-test was used for statistical analysis and $P$ values less than 0.05 were not considered to be statistically significant.

\section{Results}

\section{Experiment I: evaluation by the wound/ affected area method}

The wound/affected area of the corneal epithelium decreased with time, recording (mean [standard deviation], 34.4 [5.0] $\mathrm{mm}^{2}$ ) at 30 minutes, $11.8(5.9) \mathrm{mm}^{2}$ at 24 hours, $0.7(0.5) \mathrm{mm}^{2}$ at 48 hours, and almost $0 \mathrm{~mm}^{2}$ at 72 hours $(\mathrm{N}=4)$. During the period from 30 minutes to 48 hours after detachment, the wound/affected areas decreased approximately linearly with time, and the wound healing rate was determined to be $0.71 \mathrm{~mm}^{2} / \mathrm{h}$ from the regression curve (Figure 2A). The wound/affected area determined by fluorescein staining decreased gradually over time, and there was little chromatic response at 48 hours (Figure 2B).

\section{Experiment 2: evaluation with the CRD}

The \%CR decreased (mean [standard deviation], 53.6 [9.3]\%) at 30 minutes after detachment, and subsequently increased over time, recording $85.1(25.9) \%$ at 24 hours, $103.5(15.3) \%$ at 48 hours, and $104.7(18.6) \%$ at 72 hours $(\mathrm{N}=4$; Figure 3).

\section{Experiment 3: relationship between wound/affected area $\left(\mathrm{mm}^{2}\right)$ and \%CR}

The \%CR was 73.14 (9.20)\%, 55.48 (2.02)\%, 53.57 (9.25)\%, and $34.92(2.67) \%(\mathrm{~N}=7)$ when the filter paper diameters were $9 \mathrm{~mm}$ (area, $\left.63.59 \mathrm{~mm}^{2}\right), 6 \mathrm{~mm}\left(28.26 \mathrm{~mm}^{2}\right), 4 \mathrm{~mm}$ $\left(12.56 \mathrm{~mm}^{2}\right)$, and $1.75 \mathrm{~mm}\left(2.27 \mathrm{~mm}^{2}\right)$, respectively. Thus, the $\% \mathrm{CR}$ decreased as the wound/affected area increased, and there was a linear correlation $(\mathrm{Y}=0.55 \mathrm{x}+69.01)$ between these two variables $(\mathrm{N}=4-7$; Figure 4).

\section{Experiment 4: measurement of electrical resistance with the corneal chamber device (in vitro experiment)}

When the $\% \mathrm{CR}$ was measured with the corneal chamber measuring device, the $\% \mathrm{CR}$ in the whole cornea was $100 \%$, whereas the rate of corneal epithelial injury was $79.5(8.4) \%$ for a filter paper diameter of $1.75 \mathrm{~mm}$ (area, $2.27 \mathrm{~mm}^{2}$ ), $70.2(7.1) \%$ for $4 \mathrm{~mm}$ (area, $\left.12.56 \mathrm{~mm}^{2}\right), 64.9$ (3.7)\% for $6 \mathrm{~mm}$ (area, $28.26 \mathrm{~mm}^{2}$ ), and $62.0(6.8) \%$ for $9 \mathrm{~mm}$ (area, $\left.63.59 \mathrm{~mm}^{2}\right)(\mathrm{N}=4$; Figure 5). The ratio of resistance in the corneal epithelium was $97.5(0.1) \%$ of the whole cornea.

\section{Discussion}

The electrophysical properties of a cell or tissue can be determined by passing an electric current through the cell or tissue and measuring the voltage drop and potential difference across the tissue. When the current delivered and the voltage measured are known, the resistance of the tissue can be calculated using Ohm's Law: resistance $(\Omega)$ is equal to the voltage (V) divided by the current (I in amperes). The purpose of this study was to determine whether CR can be used to assess the degree of injury of CECs. To accomplish this, we delivered electrical pulses to the cornea using a CL containing two concentric electrodes and recorded the voltage drop across the cornea using the same electrodes. This device is unique in that electricity is the input medium, and the device is composed of corneal electrodes assuming the form of a CL, enabling noninvasive measurement.

With this device, $\Omega$ was used as the unit of CR obtained. This was because the thickness of the cornea, $\mathrm{L}[\mathrm{m}]$, and the sectional area of the cornea, $\mathrm{A}\left[\mathrm{m}^{2}\right]$, were the same for a comparative investigation in the same eye, and it is considered that the difference in the resistance $(\Omega)$ represents the corneal epithelial injury. The electrical resistance $[\Omega]$ can be obtained from the following equation. Given that the percentage electrical resistance is rho $(\rho)$, the length of the conductor is $\mathrm{L}[\mathrm{m}]$, and the sectional area of the conductor is 


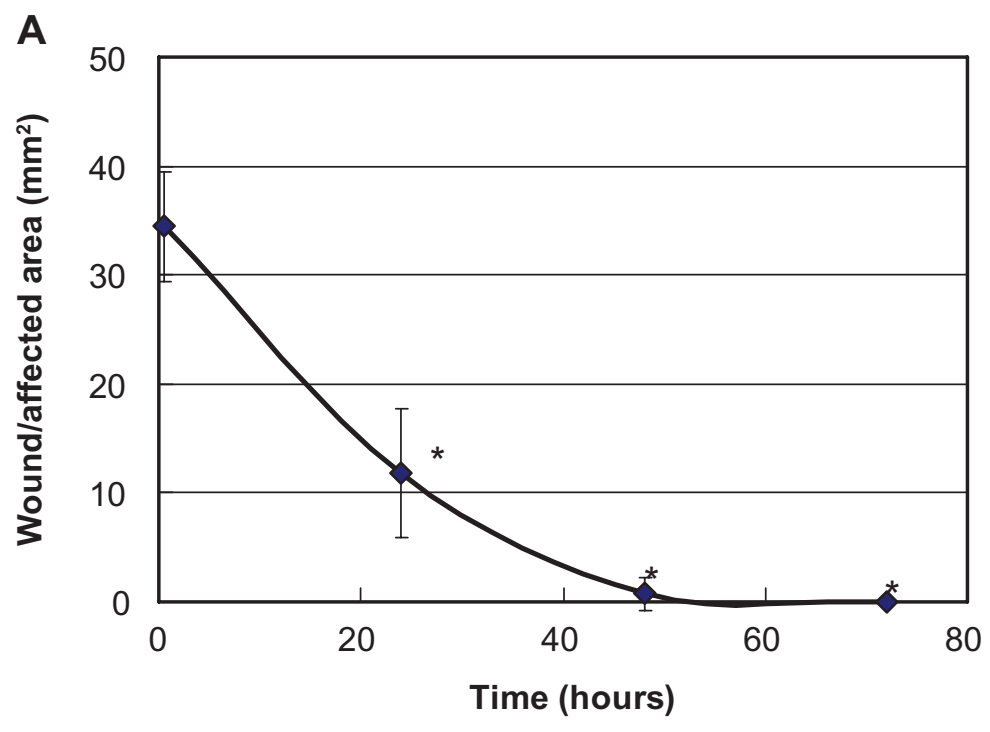

B

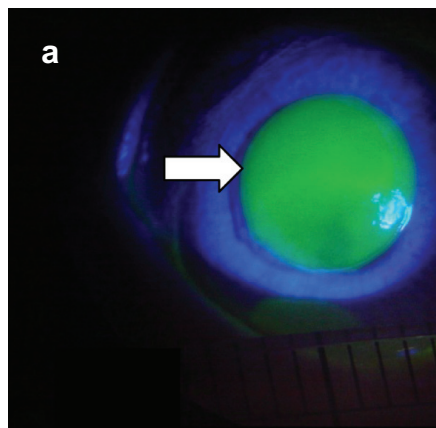

c

d

Figure 2 Evaluation of the wound/affected area method (A) and fluorescein staining (B)

Notes: During the period from 30 minutes to 48 hours after detachment, the wound/affected areas decreased approximately linearly with time. Data are means \pm standard deviation of values from four eyes. $* P<0.05$ versus the corresponding value for after 30 minutes (Student's $t$-test). The wound/affected area as determined by fluorescein staining decreased gradually over time, and there was little chromatic response at 48 hours. The arrow shows the corneal epithelium defect observed by fluorescein staining. a: 30 minutes after detachment; b: 24 hours after detachment; c: 48 hours after detachment; and d: 72 hours after detachment.

$\mathrm{A}\left[\mathrm{m}^{2}\right]$, the value is determined from the following equation: $\mathrm{R}=\rho \mathrm{L} / \mathrm{A}[\Omega]$, that is, $\rho=\mathrm{RA} / \mathrm{L}[\Omega \cdot \mathrm{m}]$.

In this experiment, full-thickness detachment of the corneal epithelium was induced with n-heptanol according to the method reported by Cintron et al. ${ }^{9}$ The CRD was then examined to determine whether it was able to quantitatively evaluate the severity of the induced corneal injuries. The electrical resistance of the eyes with injured corneal epitheliums was markedly lower than that of intact eyes, clearly indicating that electrical CR was affected by the condition of the corneal epithelium. The present experiment additionally allowed us to confirm that the \%CR decreased as the area of corneal epithelium detachment became larger.

In the present experiment, electrical CR was measured under the application of $100 \mu \mathrm{A}$ electrical current for about 1 second. Fluorescein staining and slit-lamp biomicroscopy revealed no abnormalities in the anterior segment of each eye (conjunctiva, cornea, etc) after measurement of electrical CR with this device. The safety of the corneal electrodes of this device has been established for eyes in vivo. ${ }^{10}$ Fujikado et al 


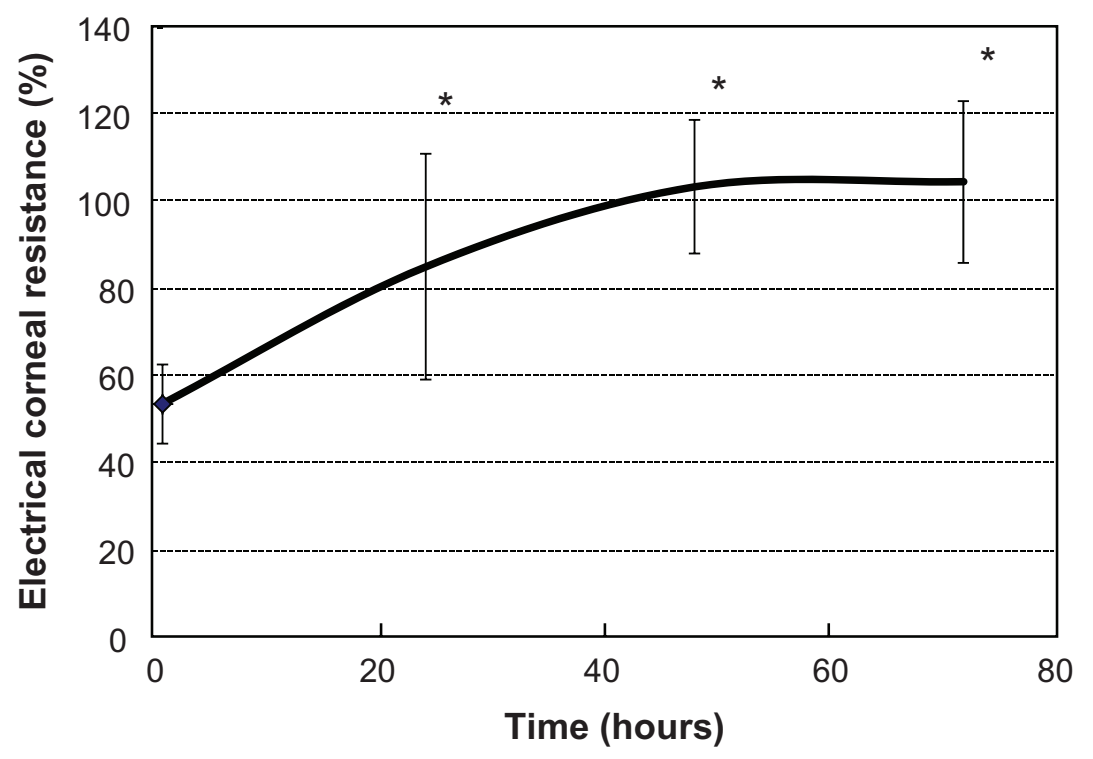

Figure 3 Evaluation with the corneal resistance device.

Notes: After induction of corneal epithelium detachment, the percentage of corneal resistance increased over time. Data are expressed as mean (standard deviation). Data are means \pm standard deviation of values from four eyes. $* P<0.05$ versus the corresponding value for after 30 minutes (Student's $t$-test).

applied electricity ( $1 \mathrm{~mA})$ repeatedly (30 minutes/session) to human eyes and confirmed the absence of disorders caused by the passage of electric currents. ${ }^{11}$ It has also been shown that the current from corneal CL electrodes passes through the cornea and is distributed within the eyeball. ${ }^{12}$

In an additional experiment that was designed to confirm that the resistance measured with the CRD reflected the corneal epithelial injury, we confirmed that the device we developed allowed quantification even in the presence of minor disorders (superficial punctate keratopathy) induced by the use of an ophthalmic solution containing benzalkonium chloride. We have already confirmed that benzalkonium chloride induced corneal epithelial injury in a dose-dependent manner. On the basis of these experimental results, we presume that this device can be used for the quantitative evaluation of corneal epithelial injury. ${ }^{13}$

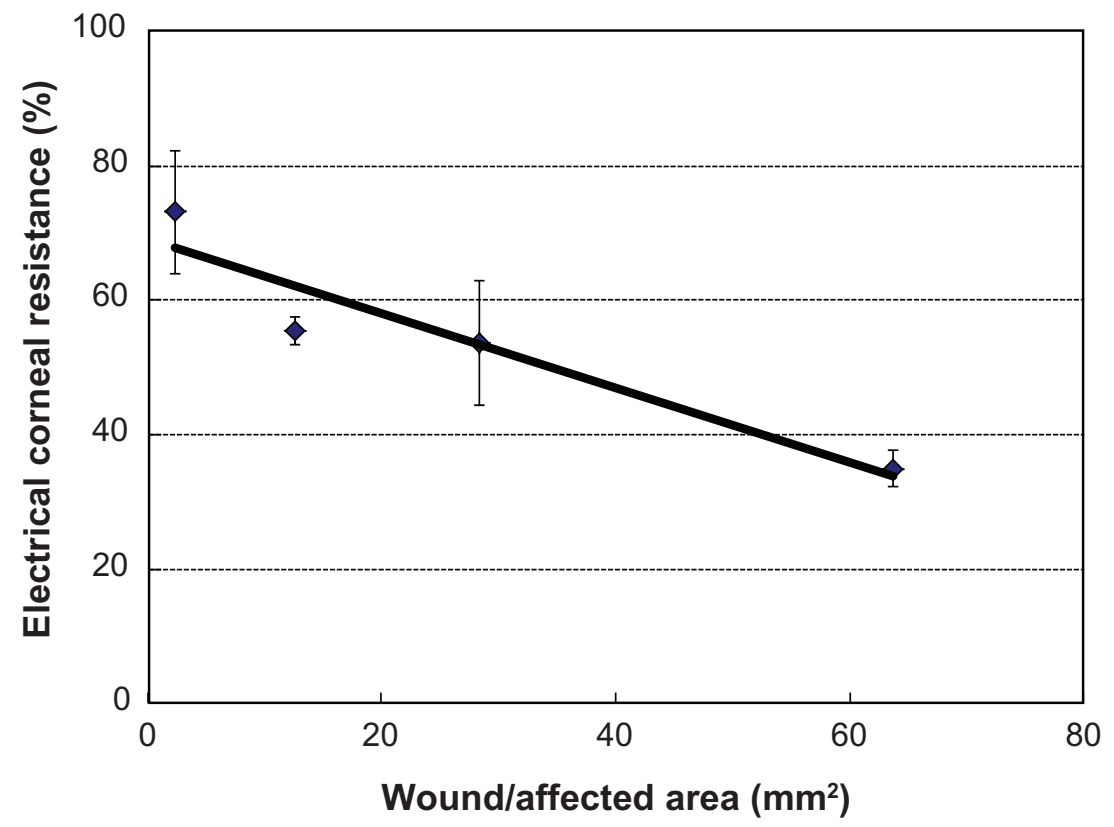

Figure 4 Relationship between wound/affected area $\left(\mathrm{mm}^{2}\right)$ and the percentage of corneal resistance.

Notes: Data are expressed as mean (standard deviation). The percentage of corneal resistance decreased as the wound/affected area increased, and there was a linear correlation $\left(Y=0.55 x+69.01, R^{2}=0.8996\right)$ between these two variables $(N=4-7)$. 

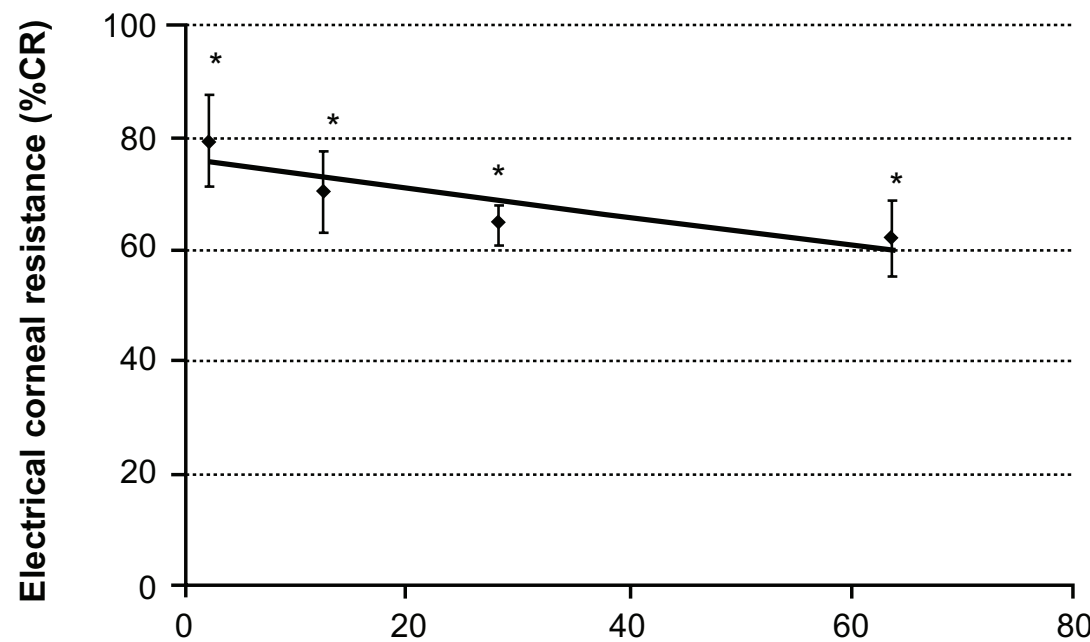

Wound/affected area $\left(\mathrm{mm}^{2}\right)$

Figure 5 Measurement of electrical resistance with the corneal chamber device (in vitro experiment).

Notes: The correlation between the percentage of corneal resistance obtained by the corneal chamber measuring device and the area $\left(\mathrm{mm}^{2}\right)$ of corneal epithelial injury is $Y=-0.25 x+75.80, R^{2}=0.7545$. The larger the area of corneal epithelial injury was, the smaller the percentage of corneal resistance was. Data are means $\pm s t a n d a r d ~ d e v i a t i o n$ of values from four eyes. $* P<0.05$ versus the corresponding value for the whole cornea (Student's $t$-test) $(N=4)$.

To evaluate the minute barrier function changes of the cornea against the corneal epithelial tissue caused by ophthalmic solutions in the market, we set one of the conditions of a corneal resistance measuring device, frequency, to be low $(1000 \mathrm{~Hz}$; generally not more than $10 \mathrm{kHz})$. It is well known that resistance of the living tissues greatly depends on frequency. Further, it is possible to measure resistance of the extracellular fluid because the resistance of the cell membrane is very strong in the low-frequency range and the electrical current flows in the extracellular region, not in the inside of the cell membrane. ${ }^{14-16}$ On the other hand, in the highfrequency range, the electrical current could easily pass the cell membrane and flow into the cells, and therefore, resistance of the intracellular and extracellular fluid was measured. ${ }^{17,18}$ By applying a low frequency of $1000 \mathrm{~Hz}$, we were able to investigate changes of the fine structure of corneal epithelial cells, which were previously impossible to measure.

Therefore, CR measured in the injury-free cornea primarily reflected the resistance of extracellular fluid (Figure 6A). Furthermore, it is known that the resistance of the CECs accounted for a high percentage (more than $90 \%$ ) of the total corneal electrical resistance. ${ }^{2}$ In the present study, a full layer of the corneal epithelium was freed by treatment with n-heptanol, which likely resulted in a sharp reduction
A

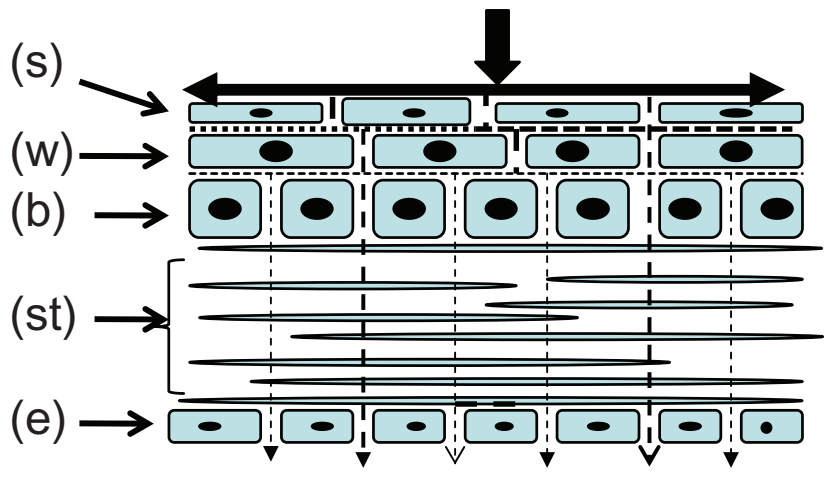

Normal
B

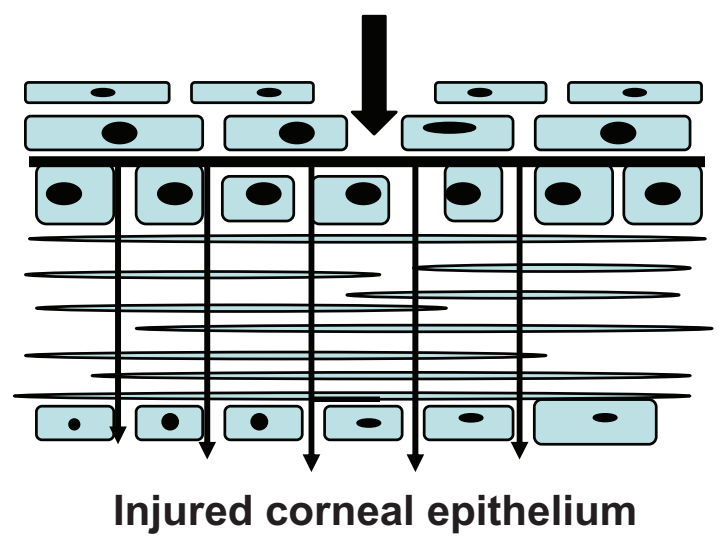

Figure 6 Microelectrode profiles across the rabbit corneal epithelium.

Notes: A diagram of the cornea showing the epithelium, a portion of stroma (st), endothelium (e), superficial (s) cells, basal (b) cells, and wing (w) cells. (A) The electric current flow is strong in the cornea surface and weak inside the cornea of normal rabbit eyes. (B) The electric current flow to the cornea increased after damage to the cornea. Arrow shows the electric current flow. 
in corneal electrical resistance and increased the flow of the electric current through the cornea (Figure 6B). We believe that the CR data obtained in the present study reflect the severity of corneal injury.

The CR obtained with the CRD in the present study showed a tendency to decrease when the degree of corneal epithelial injury increased, and these values were similar to the values obtained with the corneal chamber. We believe that the resistance obtained with the CRD reflects the injury of the CECs. From these results, it can be considered that the mechanism of the CRD is that electricity passes easily through injured corneal tissues, particularly $\mathrm{CECs}$, thereby resulting in a reduction in the electrical CR (property of electricity). That is, CR seems to reflect the degree of injury of corneal tissues, particularly that of the corneal epithelium.

Nakamura et al analyzed the time course of the area of corneal epithelium injury in an animal model of n-heptanolinduced corneal epithelium detachment and reported the following characteristics: (1) a healing rate of $0.64 \mathrm{~mm}^{2} /$ hour, (2) $50 \%$ healing achieved in 28 hours, (3) the presence of the subepithelial basement membrane, and (4) an approximately linear decrease in the wound/affected area from 12 to 48 hours after the induction of detachment. ${ }^{19}$ In addition, in the present study, the wound/affected area decreased approximately linearly during the period from 30 minutes to 48 hours after the induction of detachment, suggesting that the model we created is similar to that of Nakamura et al. When electrical CR was measured using this model of corneal injury, the area affected by corneal epithelium detachment decreased over time during the period from 30 minutes to 48 hours after induction of detachment, and CR increased linearly over time during this period. These results suggest that the elevation in CR correlates well with the decrease in the wound/affected area, and that CR closely reflects the severity of corneal injury. On the basis of these results, we think that, like fluorescein staining, examination using this device will provide a useful means of predicting the clinical course of corneal injury. Measurement of electrical CR of eyes in vivo using this device composed of corneal CL electrodes (active and indifferent electrodes) was shown to enable surrogate evaluation of corneal function and to allow quantitative analysis of test data. It was additionally confirmed that the use of the electrodes in this device enables surrogate evaluation and quantitative analysis of the barrier function of the corneal epithelium. This device is characterized by the electrophysiological method, damage quantification, real-time measurement, non-invasive quantification, and a short test time ( 5 seconds). We hope this device will be used as a method of recording the treatment course of patients.

\section{Conclusion}

The results obtained using the corneal electrode method were almost consistent with those obtained using the wound/affected area method, indicating that the corneal electrode method may enable quantitative evaluation of corneal injury.

\section{Disclosure}

The authors report no conflicts of interest in this work.

\section{References}

1. Wolosin JM. Regeneration of resistance and ion transport in rabbit corneal epithelium after induced surface cell exfoliation. J Membr Biol. 1988;104:45-55.

2. Klyce SD. Electrical profiles in the corneal epithelium. J Physiol. 1972;226:407-429.

3. Nakamura T, Yamada M, Teshima M, et al. Electrophysiological characterization of tight junctional pathway of rabbit cornea treated with ophthalmic ingredients. Biol Pharm Bull. 2007;30: 2360-2364.

4. Fukuda M, Murano H, Yamamoto K, et al. Cytotoxic effect of sodium cromoglicate ophthalmic solutions on cultured rabbit corneal cell line. Atarashii Ganka (Journal of the Eye). 2005;22:1675-1678.

5. Takahashi N. Quantitative cytotoxicity of preservatives evaluated in cell culture with Chang's human conjunctival cells - effect of temperature on cytotoxicity. Jpn J Ophthalmol. 1982;26:234-238.

6. Pellinen P, Lokkila J. Corneal penetration into rabbit aqueous humor is comparable between preserved and preservative-free tafluprost. Ophthalmic Res. 2009;41:118-122.

7. Yee RW, Norcom EG, Zhao XC. Comparison of the relative toxicity of travoprost $0.004 \%$ without benzalkonium chloride and latanoprost $0.005 \%$ in an immortalized human cornea epithelial cell culture system. Adv Ther. 2006;23:511-519.

8. Denoyer A, Ossant F, Arbeille B. Very-high-frequency ultrasound corneal imaging as a new tool for early diagnosis of ocular surface toxicity in rabbits treated with a preserved glaucoma drug. Ophthalmic Res. 2008;40:298-308.

9. Cintron C, Hassinger L, Kublin CL, Friend J. A simple method for the removal of rabbit corneal epithelium utilizing n-heptanol. Ophthalmic Res. 1979;11:90-96.

10. Yonemura D, Kawasaki K. Recording methods for clinical electroretinography. In: Hasegawa I, editor. Clinical Electroretinography. Tokyo: Igaku Shoin; 1985:6-14.

11. Fujikado T, Morimoto T, Matsushita K, Shimojo H, Okawa Y, Tano Y. Effect of transcorneal electrical stimulation in patients with nonarteritic ischemic optic neuropathy or traumatic optic neuropathy. Jpn J Ophthalmol. 2006;50:266-273.

12. Inomata K, Shinoda K, Ohde H, et al. Transcorneal electrical stimulation of retina to treat longstanding retinal artery occlusion. Graefes Arch Clin Exp Ophthalmol. 2007;245:1773-1780.

13. Fukuda M, Yamamoto K, Takahashi N, Sasaki H, Yoshikawa M. Corneal disorder quantification by corneal resistance. Atarashii Ganka (Journal of the Eye). 2007;24:521-525.

14. Sakamoto K. Tissue impedance. Clinical laboratory test. 1982; 26:413-420.

15. Schwan HP. Electrical properties of tissues and cell suspensions. Advances in Biological and Medical Physics. 1957;5:147-209. 
16. Schwan HP. Alternating current spectroscopy of biological substances. Proc.IRE. 1959;47:1841.

17. Kanai H. Physical property of living body.(2) -Electro characteristics. Med Electron Biol Eng. 1975;13:25-104.

18. Foster KR, Schwan HP. Dielectric properties of tissues and biological materials: a critical review. Crit Rev Biomed Eng. 1989;17:25-104.
19. Nakamura M, Nakano T, Mibu H, Hikida M. Hyaluronan stimulates epithelial wound healing in the rabbit cornea. Folia Ophthalmol Jpn. 1995;46:1256-1260.

\section{Publish your work in this journal}

Clinical Ophthalmology is an international, peer-reviewed journal covering all subspecialties within ophthalmology. Key topics include: Optometry; Visual science; Pharmacology and drug therapy in eye diseases; Basic Sciences; Primary and Secondary eye care; Patien Safety and Quality of Care Improvements. This journal is indexed on

Submit your manuscript here: http://www.dovepress.com/clinical-ophthalmology-journal

\section{Dovepress}

PubMed Central and CAS, and is the official journal of The Society of Clinical Ophthalmology (SCO). The manuscript management system is completely online and includes a very quick and fair peer-review system, which is all easy to use. Visit http://www.dovepress.com/ testimonials.php to read real quotes from published authors. 